Article

\title{
Performance Degradation of Surface PMSMs with Demagnetization Defect under Predictive Current Control
}

\author{
Lynn Verkroost ${ }^{1,2} * \mathbb{D}$, Joachim Druant ${ }^{1,2}$, Hendrik Vansompel ${ }^{1,2} \mathbb{D}$, Frederik De Belie ${ }^{1,2} \mathbb{D}$ and \\ Peter Sergeant ${ }^{1,2}$ (D) \\ 1 Electrical Energy Laboratory, Department of Electrical Energy, Metals, Mechanical Constructions and \\ Systems, Ghent University, 9000 Ghent, Belgium; Joachim.Druant@UGent.be (J.D.); \\ Hendrik.Vansompel@UGent.be (H.V.); Frederik.DeBelie@UGent.be (F.D.B.); Peter.Sergeant@UGent.be (P.S.) \\ 2 Flanders Make-EEDT, The Strategic Research Centre for the Manufacturing Industry, 3001 Leuven, Belgium \\ * Correspondence: Lynn.Verkroost@UGent.be
}

Received: 16 January 2019; Accepted: 20 February 2019; Published: 26 February 2019

check for updates

\begin{abstract}
To control the current of a surface mounted permanent magnet synchronous machine fed by a two-level voltage source inverter, a large variety of control algorithms exists. Each of these controllers performs differently concerning dynamic performance and control- and voltage quality, but also concerning sensitivity to demagnetization faults. Therefore, this paper investigates the performance degradation of three advanced predictive controllers under a partial demagnetization fault. The three predictive controllers are: finite-set model based predictive control, deadbeat control, and a combination of both previous algorithms. To achieve this goal, the three predictive controllers are first compared under healthy conditions, and afterwards under a partial demagnetization fault. A PI controller is added to the comparison in order to provide a model-independent benchmark. Key performance indicators, obtained from both simulations and experimental results on a $4 \mathrm{~kW}$ axial flux permanent magnet synchronous machine with yokeless and segmented armature topology, are introduced to enable a quantification of the performance degradation of the controllers under a demagnetization fault. A general conclusion is that the deadbeat controller shows superior control quality, even under partial demagnetization.
\end{abstract}

Keywords: deadbeat control; demagnetization; finite-set model based predictive control; permanent magnet synchronous machines; predictive control

\section{Introduction}

Their high efficiency, high power density, low weight and compactness make axial flux permanent magnet synchronous machines (AFPMSMs) with yokeless and segmented armature (YASA) topology - consisting of one stator and two rotors, as shown in Figure 1-very suitable for use in the context of sustainable energy conversion, transport, and industrial applications, and in particular for electric vehicles and small to medium power range wind energy systems [1,2]. As these application fields require high torque performance, AFPMSMs are frequently used in combination with high-performance current control techniques, such as predictive control [3].

A first predictive control strategy that is frequently mentioned in literature is finite-set model based predictive control (FS-MBPC) [3-6]. FS-MBPC determines in each update period $T_{\mathrm{u}}$ of the controller the future system state for each of the finite set of applicable steering actions. In case of an AFPMSM fed by a three-phase two-level voltage source inverter (2L-VSI), these steering actions are the eight possible switch states of the inverter. A cost function is used to select the most appropriate steering action, which is applied to the system during the entire following update period. One of the 
main advantages of this type of control is the fact that the cost function can be adapted in order to include extra requirements on the control actions [7]. A disadvantage of this method, however, is its large computational burden to determine the new system state for each of the possible steering actions. Furthermore, this control method leads to a variable switching frequency $f_{\text {switch }}$, making filter design more complicated [8].

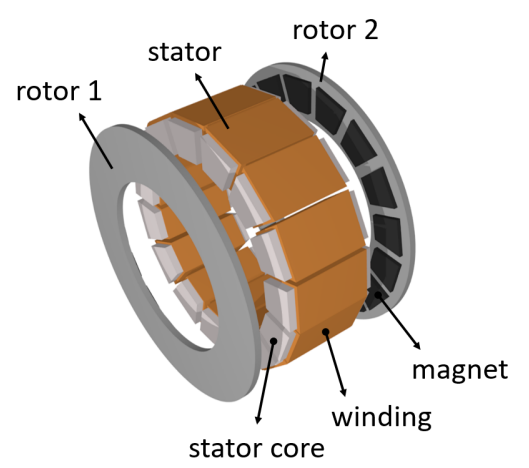

Figure 1. Axial flux permanent magnet synchronous machine (AFPMSM) with yokeless and segmented armature (YASA) topology.

A second predictive control strategy that is considered in this paper is called deadbeat (DB) control [9-11]. Contrary to FS-MBPC, DB control uses an inverse system model for the immediate computation of the system input required to reach a certain setpoint in a finite amount of time steps (preferably one). For an AFPMSM fed by a 2L-VSI, this means that a reference voltage is calculated, which is applied to the machine by means of pulse width modulation (PWM). The applicable voltage during one time period of the control algorithm is hence not restricted to the eight voltage vectors of the 2L-VSI anymore, resulting in less current ripple. However, the possibility to easily express secondary control goals is lost in this approach, as no cost function is involved.

Therefore, a third predictive control algorithm, combining the features of both FS-MBPC and DB control, is considered in this paper: MBPC with duty cycle calculation, as proposed in $[3,12]$. The working principle is the same as for standard FS-MBPC, with the only difference that the DB principle is used to determine an appropriate duty cycle for each of the six active voltage vectors of the 2L-VSI, allowing to change the amplitude of these voltage vectors. The ability to express secondary control goals by means of a cost function is maintained as well.

Since predictive control is based on a system model, its performance strongly depends on the model parameter accuracy [13-16], and for PMSMs especially on the rotor flux [17]. High temperatures and currents, operating under strong field-weakening conditions, mechanical stresses, magnet cracks and mechanical imperfections may cause (partial) demagnetization [18-21]. In [18], it is explained how partial demagnetization faults, in which not all the magnets are demagnetized evenly, can occur due to multiple short-circuit faults. As in PMSMs, the rotor flux is equal to the permanent magnet (PM) flux linkage, demagnetization causes prediction errors, leading to static errors and oscillations in the stator currents, and consequently in the torque output. In literature, the performance degradation of predictive control under parameter mismatch is frequently mentioned [3,9,22], and several methods are proposed to counteract the effect of a demagnetization fault. In [23], for instance, a fast and a slow recursive least squares (RLS) algorithm are combined to estimate the stator resistance, machine inductances and rotor magnetic flux of PMSMs online, in order to improve the dynamic drive performance in case of perturbation. The authors of [24] enhanced the robustness of the DB controller by adding a discrete-time integral term to the deadbeat current prediction, while the authors of [25] developed an error correction technique based on the discrete Lyapunov stability theorem. In [26], the prediction accuracy is improved by adding the last prediction error observed for a particular switch state to the new prediction for the switch state under consideration. The methods proposed in [27-29], 
on the other hand, ameliorated standard predictive control by making use of observers. However, little attention has been given to the difference in performance degradation of the different predictive controllers under demagnetization faults, and especially not under partial demagnetization faults. Nevertheless, since lots of applications require high reliability of electrical machines and their control under extreme circumstances, the performance degradation of a controller under demagnetization faults can be a decisive argument in the choice for a certain type of predictive controller.

Therefore, the aim of this article is to compare the above-mentioned predictive controllers with each other concerning performance degradation under a partial demagnetization fault. Since the PI controller is still one of the most frequently used controllers in industry [30] and does not make use of a system model, the PI controller will serve as a benchmark for the more advanced and more complex predictive controllers. Although comparative studies between two or more predictive controllers, or between a certain type of predictive controller and a PI controller already exist in literature for a healthy machine $[3,4,9,10,12,22,31]$, such a global comparison of the three abovementioned predictive controllers and a PI controller has—-to the authors' best knowledge-never been performed for a machine with a partial demagnetization fault.

This paper starts with a description of the state-space model of the AFPMSM that is used by the predictive controllers. In Section 3, the working principle of the different control strategies is summarized, after which their performance is compared in Section 4.1 under healthy operation. Section 4.2 covers the effect of a partial demagnetization fault. All the obtained simulation results are experimentally verified on a $4 \mathrm{~kW}$ prototype of an AFPMSM with surface mounted PMs, a YASA topology and fractional slot windings [1], fed by a three-phase 2L-VSI. The comparative study covers both steady-state and transient operation, under a variety of working conditions. Eventually, the conclusions are presented in Section 5 .

\section{Machine Model Description}

The dynamic electrical equations of the stator windings of the AFPMSM in a synchronous $d q$-reference frame with time step $\Delta t$, are expressed in the following discrete state-space model:

$$
\left[\begin{array}{c}
i_{d}^{k+1} \\
i_{q}^{k+1}
\end{array}\right]=\left[\begin{array}{cc}
1-\frac{R_{s} \Delta t}{L_{d}} & \omega^{k} \Delta t \\
-\omega^{k} \Delta t & 1-\frac{R_{s} \Delta t}{L_{q}}
\end{array}\right]\left[\begin{array}{c}
i_{d}^{k} \\
i_{q}^{k}
\end{array}\right]+\left[\begin{array}{cc}
\Delta t & 0 \\
L_{d} & \\
0 & \frac{\Delta t}{L_{q}}
\end{array}\right]\left[\begin{array}{c}
v_{d}^{k} \\
v_{q}^{k}
\end{array}\right]+\left[\begin{array}{c}
0 \\
-\omega^{k} i_{\mathrm{mag}} \Delta t
\end{array}\right] .
$$

Only the stator windings are described, as the considered AFPMSM possesses no rotor windings.

Table 1 lists the involved machine parameters for the prototype of the AFPMSM used throughout this paper. Since this prototype has surface mounted PMs, the stator inductances $L_{q}$ and $L_{d}$ are approximately equal. $\omega^{k}(\mathrm{rad} / \mathrm{s})$ represents the electrical speed at discrete time instant $k ; i_{\text {mag }}$ is a constant equivalent current along the $d$-axis, representing the PMs and resulting in the same flux level as generated by the PMs.

The developed electromagnetic torque $T_{\mathrm{em}}$ is directly related to $i_{q}$ :

$$
T_{\mathrm{em}}^{k}=\frac{3}{2} N_{p} L_{d} i_{\mathrm{mag}} i_{q}^{k}
$$

Hence, a reference value $i_{q}^{*}$ can be used to substitute a reference value $T_{\mathrm{em}}^{*}$. For surface-mounted PMSMs, maximum torque per ampere (MTPA) is obtained by fixing $i_{d}^{*}$ to zero. 
Table 1. Machine parameters.

\begin{tabular}{lcc}
\hline Parameter & Symbol & Value \\
\hline Number of pole pairs & $N_{p}$ & 8 \\
Rated power $(\mathrm{kW})$ & $P_{\mathrm{n}}$ & 4 \\
Rated speed $(\mathrm{rpm})$ & $N_{\mathrm{n}}$ & 2500 \\
Rated torque $(\mathrm{Nm})$ & $T_{\mathrm{n}}$ & 15 \\
Rated voltage $(\mathrm{V})$ & $V_{\mathrm{n}}$ & 152 \\
Stator inductance $(\mathrm{mH})$ & $L_{q}=L_{d}$ & 2.54 \\
Stator resistance $(\mathrm{m} \Omega)$ & $R_{\mathrm{s}}$ & 325 \\
Mechanical inertia $\left(\mathrm{kg} \cdot \mathrm{m}^{2}\right)$ & $J$ & 0.0024 \\
Equivalent permanent magnet $(\mathrm{PM})$ current $(\mathrm{A})$ & $i_{\text {mag }}$ & 41.77 \\
\hline
\end{tabular}

\section{Predictive Control Schemes}

\subsection{Finite-Set Model Based Predictive Control}

The control scheme of FS-MBPC is presented in Figure 2b. Its working principle is illustrated in Figure 3 and is discussed in detail in [4]. Three important steps can be defined: estimation, prediction, and optimization. First, the system state $x^{k+1}=\left[i_{d}^{k+1}, i_{q}^{k+1}\right]$ at discrete time instant $k+1$ is estimated by means of the state-space model (1), a measurement of the system state $x^{k}$ at instant $k$, and knowledge of the applied switch state $S^{k}$ of the 2L-VSI. This estimate is then used to predict the system state $x^{k+2}$ for each of the eight switch states of the 2L-VSI. Finally, a cost function $J$ is used to select the optimal switch state $S^{k+1}$, bringing the system state $x^{k+2}$ closest to its setpoint $\left[i_{d}^{*}, i_{q}^{*}\right]$ :

$$
J^{k+1}=\left(\hat{i}_{q}^{k+2}-i_{q}^{*}\right)^{2}+W_{I}\left(\hat{i}_{d}^{k+2}-i_{d}^{*}\right)^{2} .
$$

This optimal switch state is applied to the system during the interval $k+1 \rightarrow k+2$, as is illustrated in Figure $4 \mathrm{a}$, after which the algorithm is restarted. It is noteworthy that only the eight voltage vectors-according to the eight different switch states of the three-phase 2L-VSI—can be applied to the AFPMSM during $T_{\mathrm{u}}$, yielding a high current ripple.

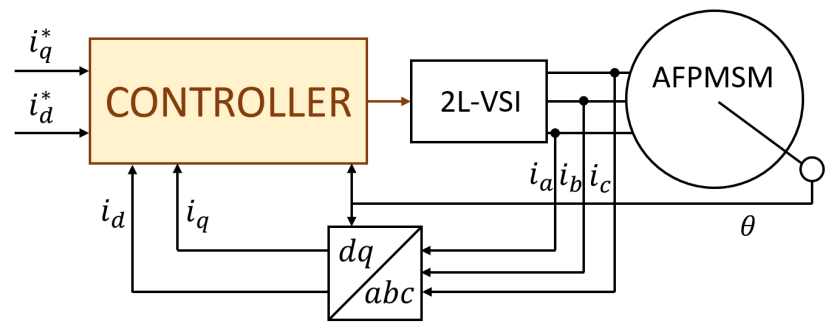

(a)

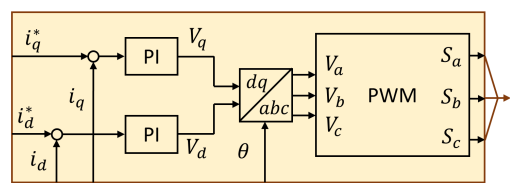

(b)

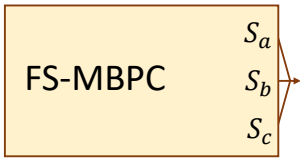

(c)

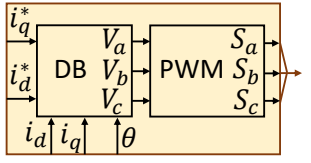

(d)

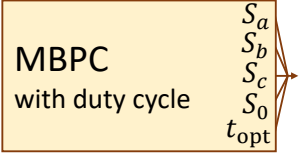

(e)

Figure 2. (a) General control scheme, with the four examined controllers: (b) PI control; (c) finite-set model based predictive control; (d) deadbeat control; (e) model based predictive control with duty cycle calculation. 


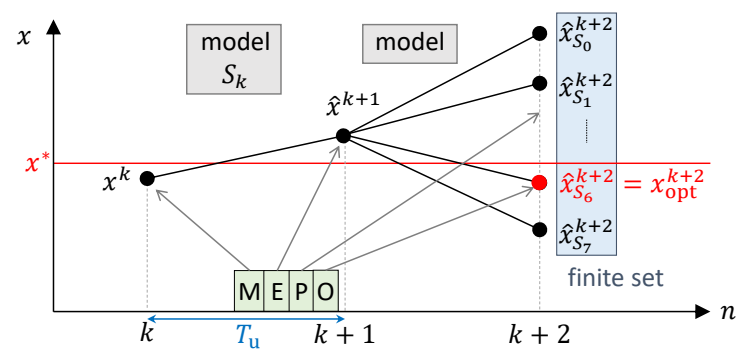

Figure 3. Working principle of FS-MBPC, visualizing the basic steps: measurement (M), estimation (E), prediction $(\mathrm{P})$, and optimization $(\mathrm{O})$.

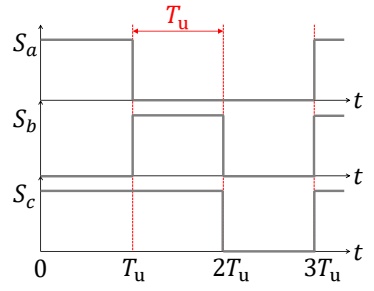

(a)

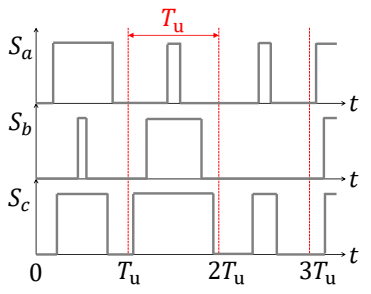

(b)

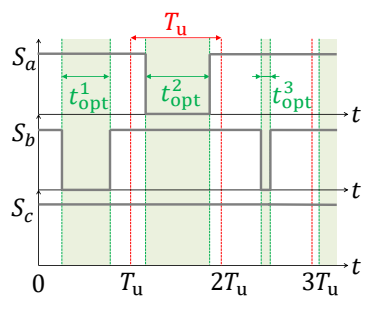

(c)

Figure 4. Difference in switching between (a) FS-MBPC; (b) PI and DB control; (c) MBPC with duty cycle calculation.

\subsection{Deadbeat Control}

The control scheme and working principle of DB control are illustrated in Figures $2 \mathrm{c}$ and 5 , respectively. Its working principle is elaborated in [4]. Contrary to FS-MBPC, DB control comprises only two major steps: estimation and calculation of the DB voltage reference. First, the system state $x^{k+1}$ is estimated by means of the state-space model (1), the measured state $x^{k}$, and the stator voltage reference $V_{k}^{*}$ determined during the previous update period $T_{\mathrm{u}}$. Secondly, the state-space model (1) is inversed, in order to determine the voltage $V_{k+1}^{*}$ required to bring the system to its setpoint: $\left[\hat{i}_{d}^{k+2}, \hat{i}_{q}^{k+2}\right]=\left[i_{d}^{*}, i_{q}^{*}\right]:$

$$
\left\{\begin{array}{l}
v_{d}^{k+1}=R_{\mathrm{s}} \hat{i}_{d}^{k+1}+\frac{L_{d}}{T_{\mathrm{u}}}\left(i_{d}^{*}-\hat{i}_{d}^{k+1}\right)-\omega^{k} L_{q} \hat{i}_{q}^{k+1}, \\
v_{q}^{k+1}=R_{\mathrm{s}} \hat{i}_{q}^{k+1}+\frac{L_{q}}{T_{\mathrm{u}}}\left(i_{q}^{*}-\hat{i}_{q}^{k+1}\right)+\omega^{k} L_{d}\left(\hat{i}_{d}^{k+1}+i_{\mathrm{mag}}\right) .
\end{array}\right.
$$

Eventually, a PWM algorithm determines the sequence of switch states that needs to be applied during $T_{\mathrm{u}}$, in order to generate this reference voltage $V_{k+1}^{*}$ on average during the time interval $k+1 \rightarrow k+2$. Since PWM enables varying the duty cycle of each inverter leg separately-as is illustrated in Figure $4 \mathrm{~b}$-both the magnitude and the direction of the average applied voltage vector become variable.

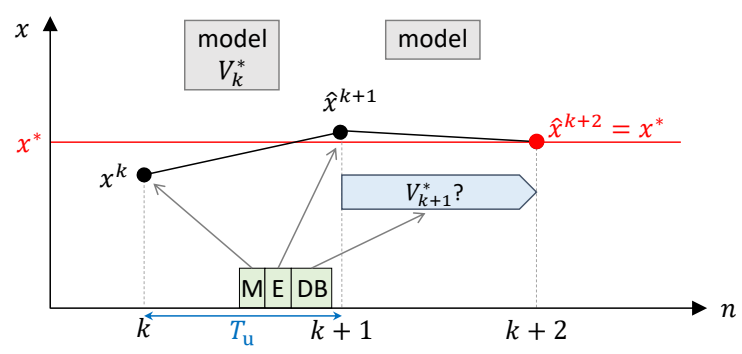

Figure 5. Working principle of DB control, visualizing the basic steps: measurement (M), estimation (E), and deadbeat voltage reference calculation (DB). 


\subsection{MBPC with Duty Cycle Calculation}

Figure $2 \mathrm{~d}$ shows the control scheme for MBPC with duty cycle calculation. Its working principle is similar to that of standard FS-MBPC, and is elaborated in [4]. Three important steps can be defined in the working principle: estimation, prediction and optimization. Contrary to FS-MBPC, only the six active voltage vectors of the three-phase 2L-VSI are evaluated in the prediction step. An appropriate duty cycle $t_{\text {opt }}$ is determined for each of these active voltage vectors, by stating that $\hat{i}_{q}^{k+2}$ should equal the setpoint $i_{q}^{*}$. First, seven pairs of current slopes are calculated by means of the dynamical Equations (1): six pairs of current slopes $s_{i}(i=1, \ldots, 6)$ for the fraction of the period in which one of the six active voltage vectors is applied, and one pair of current slopes $s_{0}$ for when a null vector is applied:

$$
\begin{gathered}
\left\{\begin{array}{l}
s_{d, 0}^{k+1}=\frac{1}{L_{d}}\left[-R_{\mathrm{s}} \hat{i}_{d}^{k+1}+\omega^{k} L_{q} \hat{i}_{q}^{k+1}\right], \\
s_{d, i}^{k+1}=\frac{1}{L_{d}}\left[v_{d, i}^{k+1}-R_{\mathrm{s}} \hat{i}_{d}^{k+1}+\omega^{k} L_{q} \hat{i}_{q}^{k+1}\right],
\end{array}\right. \\
\left\{\begin{array}{l}
s_{q, 0}^{k+1}=\frac{1}{L_{q}}\left[-R_{\mathrm{s}} \hat{i}_{q}^{k+1}-\omega^{k} L_{d}\left(\hat{i}_{d}^{k+1}+i_{\mathrm{mag}}\right)\right], \\
s_{q, i}^{k+1}=\frac{1}{L_{q}}\left[v_{q, i}^{k+1}-R_{\mathrm{s}} \hat{i}_{q}^{k+1}-\omega^{k} L_{d}\left(\hat{i}_{d}^{k+1}+i_{\mathrm{mag}}\right)\right] .
\end{array}\right.
\end{gathered}
$$

The optimal duration $t_{\mathrm{opt}, \mathrm{i}}^{k+1}$ for each of the active voltage vectors is computed by means of the deadbeat principle:

$$
i_{q}^{*}=\hat{i}_{q}^{k+2}=\hat{i}_{q}^{k+1}+s_{q, 0}^{k+1}\left(T_{\mathrm{u}}-t_{\mathrm{opt}, i}^{*}\right)+s_{q, i}^{k+1} t_{\mathrm{opt}, i}^{*}
$$

and consequently:

$$
\begin{gathered}
t_{\mathrm{opt}, i}^{*}=\frac{i_{q}^{*}-\hat{i}_{q}^{k+1}-s_{q, 0}^{k+1} T_{\mathrm{u}}}{s_{q, i}^{k+1}-s_{q, 0}^{k+1}}, \\
\begin{cases}t_{\mathrm{ot}, i}^{k+1}=0, & \text { if } t_{\mathrm{opt}, i}^{*}<0, \\
t_{\mathrm{opt}, i}^{k+1}=t_{\mathrm{opt}, i}^{*} & \text { if } 0 \leq t_{\mathrm{opt}, i}^{*} \leq T_{\mathrm{u}}, \\
t_{\mathrm{opt}, i}^{k+1}=T_{\mathrm{u}}, & \text { if } T_{\mathrm{u}}<t_{\mathrm{opt}, i}^{*} .\end{cases}
\end{gathered}
$$

During the remaining fraction of $T_{\mathfrak{u}}$, the null vector that requires the lowest number of switches to change their state, is applied. Eventually, the current components at instant $k+2$ can be predicted based on $s_{0}^{k+1}, s_{i}^{k+1}$ and $t_{\mathrm{opt}, i}^{k+1}$ :

$$
\begin{aligned}
& \hat{i}_{q}^{k+2}=\hat{i}_{q}^{k+1}+s_{q, 0}^{k+1}\left(T_{\mathbf{u}}-t_{\mathrm{opt}, i}^{k+1}\right)+s_{q, i}^{k+1} t_{\mathrm{opt}, i^{\prime}}^{k+1} \\
& \hat{i}_{d}^{k+2}=\hat{i}_{d}^{k+1}+s_{d, 0}^{k+1}\left(T_{\mathbf{u}}-t_{\mathrm{opt}, i}^{k+1}\right)+s_{d, i}^{k+1} t_{\mathrm{opt}, i}^{k+1} .
\end{aligned}
$$

The optimal combination of active voltage vector $S^{k+1}$ and duty cycle $t_{\mathrm{opt}, i}^{k+1}$ is determined by means of cost function (3). Contrary to DB control followed by PWM, the optimization of the duty cycle only allows changing the magnitude of the applied voltage vector, and not its direction. The difference in switching is illustrated in Figure 4.

\section{Simulation and Experimental Results}

The performance of the predictive controllers is first compared in simulation, in a MATLAB $^{\circledR}$ (ResearchR2016b, MathWorks, Natick, MA, USA) and Simulink ${ }^{\circledR} \quad$ (ResearchR2016b, MathWorks, Natick, MA, USA) environment. Representative noise levels—obtained from previous measurements on the test setup-are added to the angle, speed and current signals, in order to make the simulations more realistic. To provide a model-independent benchmark for the comparison of the predictive controllers, simulations are conducted for a PI controller with anti-windup and parameters $K_{p}=4.13$ and $K_{i}=3206.4$ (leading to a cut-off frequency $\omega_{c}$ of $2247.56 \mathrm{rad} / \mathrm{s}$ ) as well. Its control scheme is presented in Figure 2a. Afterwards, the simulation results are experimentally 
verified on a $4 \mathrm{~kW}$ test setup, presented in Figure 6. The mechanical speed of the machine is held constant by a $7.5 \mathrm{~kW}, 3000 \mathrm{rpm}$ asynchronous motor powered by a bidirectional Siemens Sinamics drive (Munich, Germany). A torque sensor measures the mechanical power transfer between both machines. The prototype AFPMSM-designed according to the principles proposed in [1], and with the specifications given in Table 1 -is connected to a custom-made drive. The mechanical design of the AFPMSM is as such that the right rotor disc can be replaced easily by a faulty one, shown in Figure 7 . The control algorithms are implemented on a Xilinx@ Cintex(C)-7 XC7K325T FPGA (Wixom, MI, USA), embedded in a dSPACE MicroLabBox. The FPGA is programmed using the Xilinx System Generator blockset in a MATLAB(C)\&Simulink(C) environment. The chosen update frequency $f_{\mathfrak{u}}$ amounts to $10 \mathrm{kHz}$. All control signals and measurements are processed in the MicroLabBox as well.

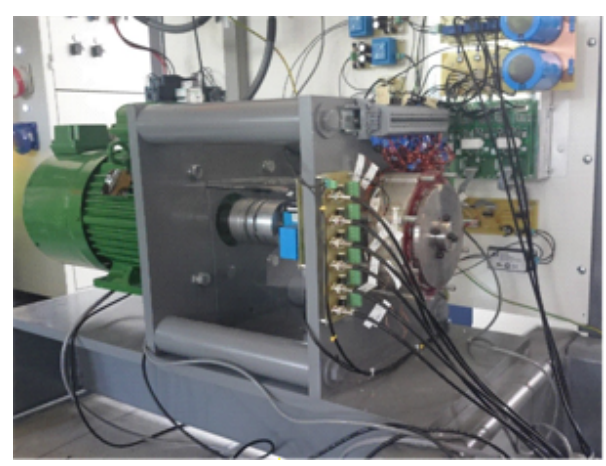

(a) Actual setup

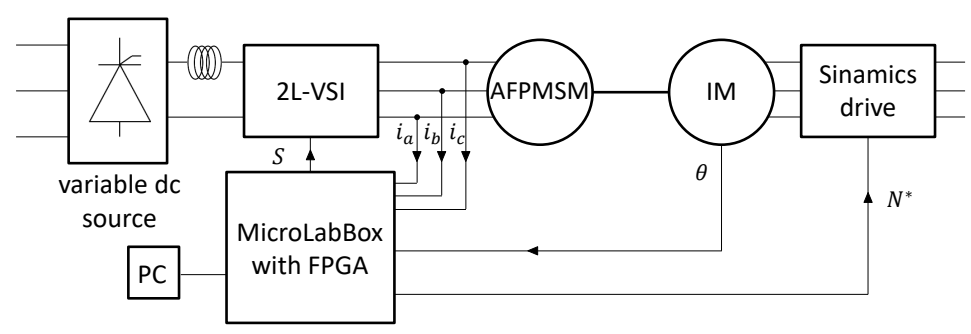

(b) Scheme

Figure 6. Test setup for the YASA AFPMSM.

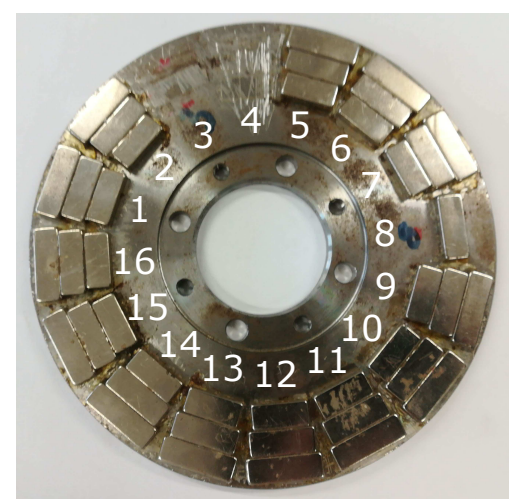

Figure 7. Faulty rotor disc with partial demagnetization: the complete third and fourth magnet, and a part of the eighth magnet are removed.

\subsection{Healthy Rotor}

The simulation and experimental results in Figure 8 show that all controllers are able to track their references $i_{q}^{*}$ and $i_{d}^{*}$ under healthy machine conditions, both in simulation and real life, for a DC-bus voltage $V_{\mathrm{dc}}$ of $200 \mathrm{~V}$ and a mechanical speed $N$ of $800 \mathrm{rpm}$. However, the fact that each controller 
results in different features of the stator current components $i_{q}$ and $i_{d}$ strikes immediately. These features will be compared in the following sections by means of key performance indicators (KPIs), presented in Figures 9a and 10a. The measured KPIs are averaged over ten measurements, and over different setpoints $i_{q}^{*}$. The effect of the working conditions on the KPIs will be investigated as well.

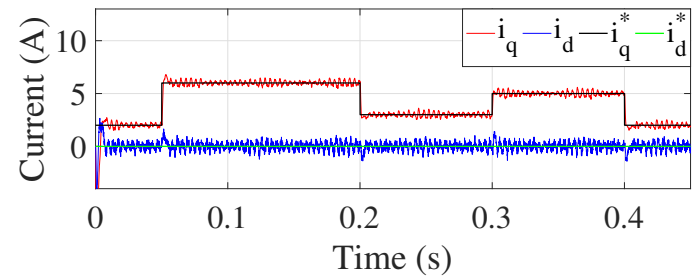

(a) simulation PI control

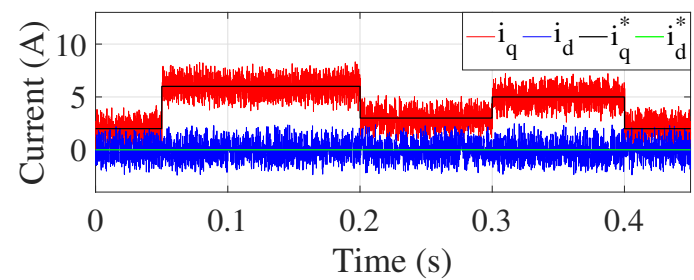

(c) simulation FS-MBPC

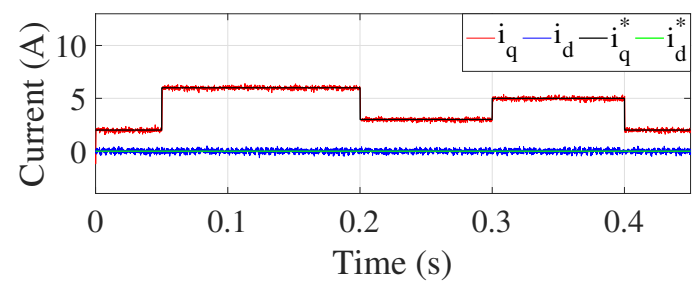

(e) simulation DB control

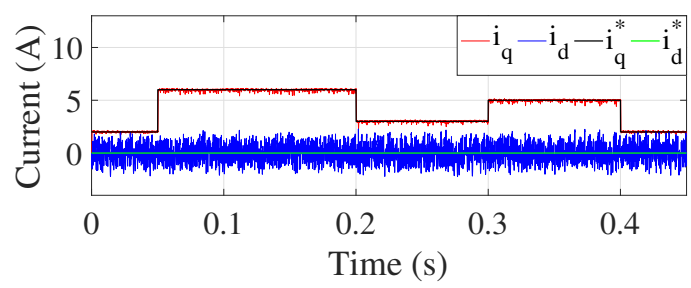

(g) simulation MBPC with duty cycle calculation

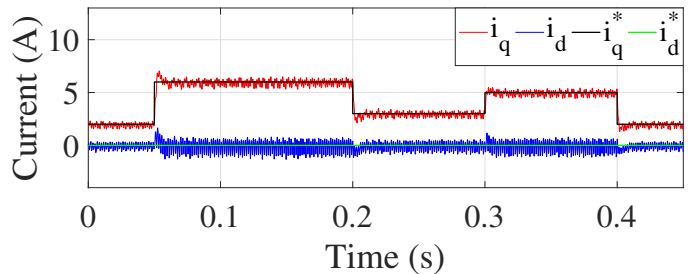

(b) experiment PI control

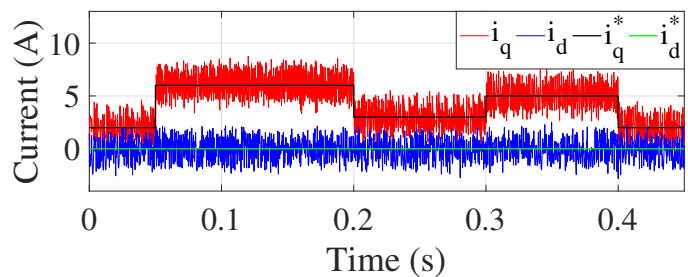

(d) experiment FS-MBPC

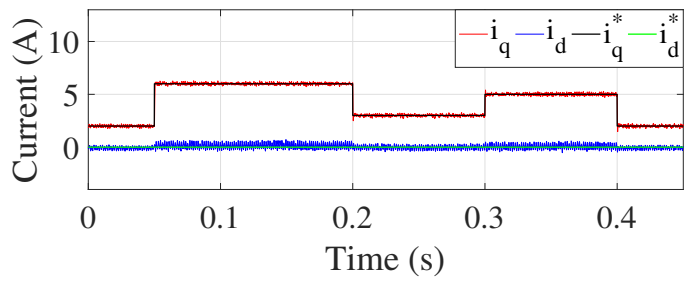

(f) experiment DB control

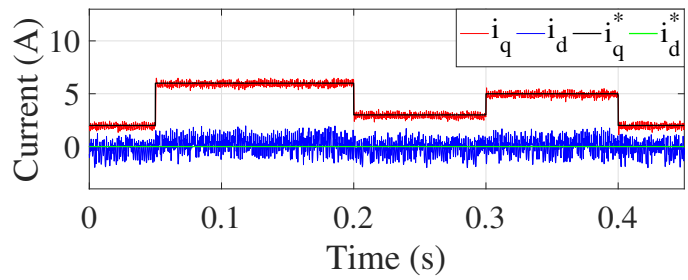

(h) experiment MBPC with duty cycle calculation

Figure 8. Simulation and experimental results for the stator current components with a healthy rotor $\left(N=800 \mathrm{rpm} ; V_{\mathrm{dc}}=200 \mathrm{~V}\right)$. FS-MBPC: finite-set model based predictive control; DB: deadbeat; MBPC: model based predictive control. 

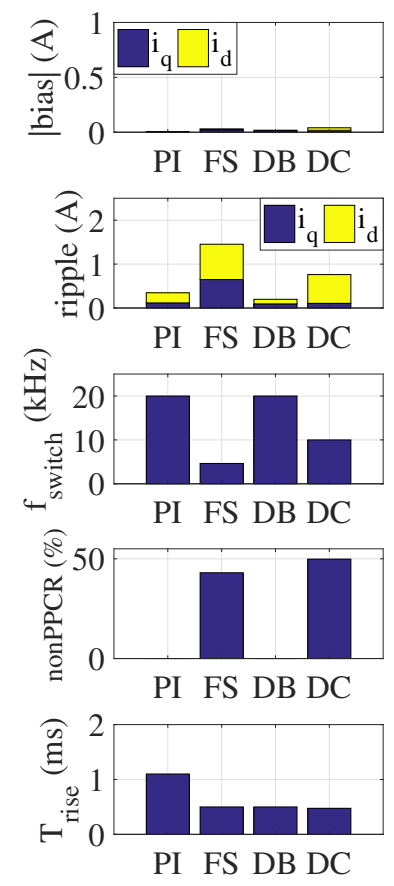

(a) healthy

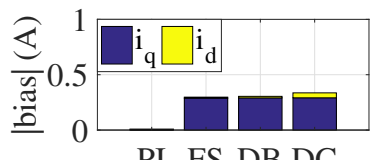

PI FS DB DC
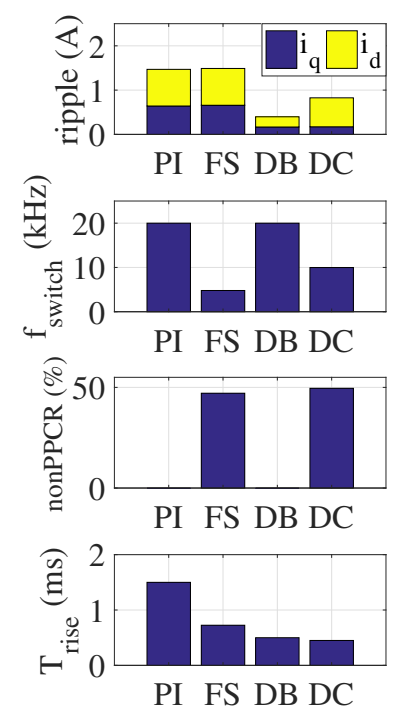

(b) faulty

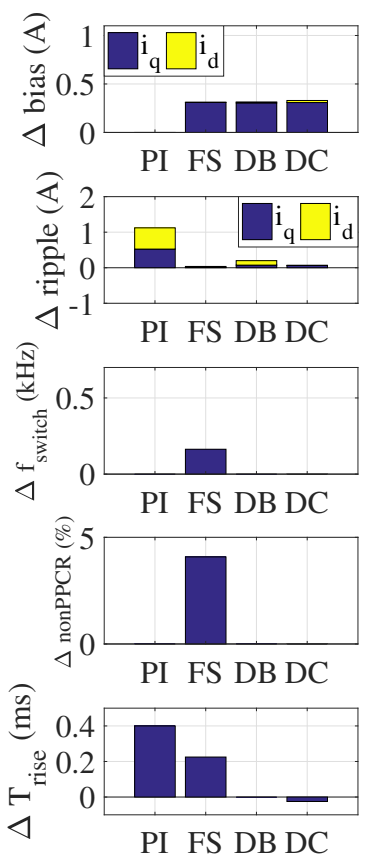

(c) effect

Figure 9. Simulated key performance indicators (KPIs) for $V_{\mathrm{dc}}=200 \mathrm{~V}$ and $N=800 \mathrm{rpm}$ (PI $=$ PI control; FS = FS-MBPC; DB = DB control; DC = MBPC with duty cycle calculation).
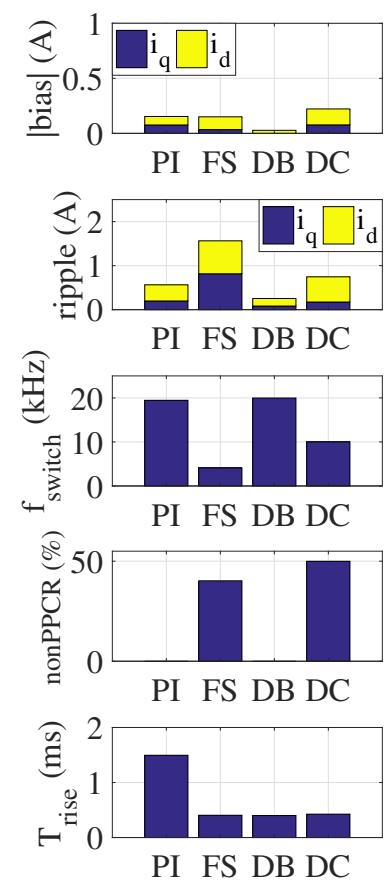

(a) healthy
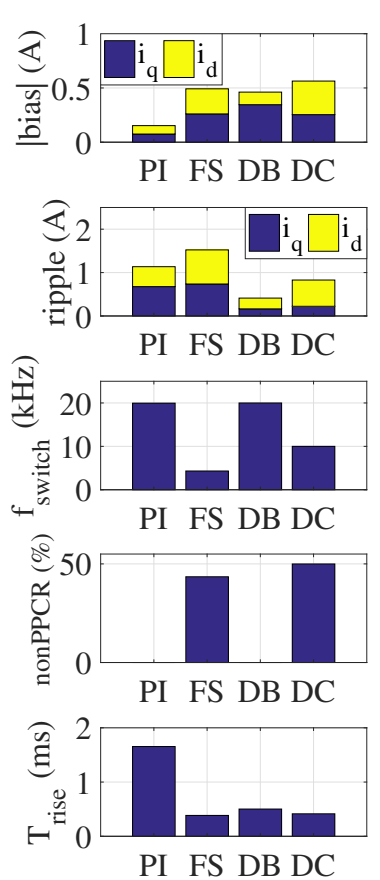

(b) faulty

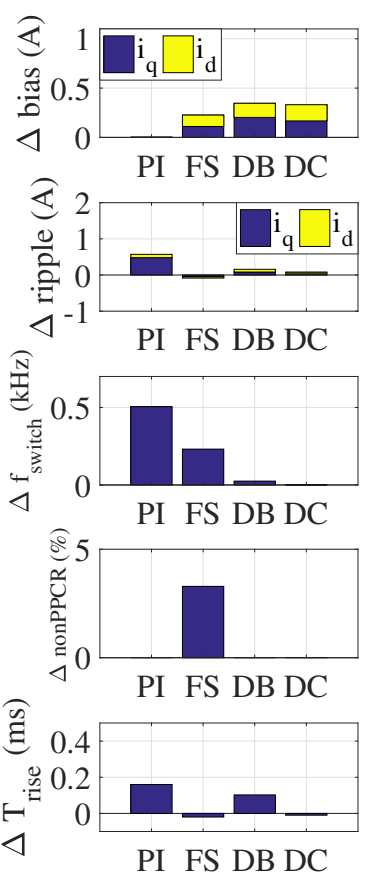

(c) effect

Figure 10. Experimental KPIs for $V_{\mathrm{dc}}=200 \mathrm{~V}$ and $N=800 \mathrm{rpm}$. 


\subsubsection{Control Quality}

The main task of the controllers is to bring the current components $i_{q}$ and $i_{d}$ to their reference values, without systematic deviation or bias. In order to quantify the effectiveness of the controllers in reaching this goal, the following KPI is calculated:

$$
\operatorname{bias}(x)=\sum_{k=1}^{m} \frac{x_{k}-x^{*}}{m}
$$

where $m$ is the amount of samples used in the calculation. In Figures 9a and 10a, it can be seen that none of the controllers results in significant bias under healthy machine circumstances.

However, a major difference between the four examined controllers is the resulting current ripple, and thus torque ripple. Not only does this current ripple cause an increase in the eddy current losses in the PMs and the stator core losses, but the related torque ripple also causes additional vibrations and noise. This feature of the controllers is quantified by means of the mean absolute deviation (MAD):

$$
\operatorname{ripple}(x)=\operatorname{MAD}(x)=\sum_{k=1}^{m}\left|\frac{\bar{x}-x_{k}}{m}\right| .
$$

$\bar{x}$ is the average value of the controlled variable $x$ over the $m$ considered samples. The results for this KPI are presented in Figures 9a and 10a for the simulations and the experiments. The DB controller significantly outperforms FS-MBPC and MBPC with duty cycle calculation concerning this feature, due to the fact that both the amplitude and the direction of its on average applied voltage vector can be varied with PWM. FS-MBPC results in real life in more than six times the level of ripple obtained by DB control. The addition of the duty cycle calculation to the FS-MBPC algorithm made only the ripple in $i_{q}$ comparable to the ripple obtained with DB control. The ripple in $i_{d}$ did not improve because the focus of the duty cycle calculation is on $i_{q}$, and not on $i_{d}$. The performance of the PI controller resembles the performance of the DB controller, since the PI controller uses PWM to apply the desired voltage as well. It must be noted, however, that this result strongly depends on the tuning of $K_{p}$ and $K_{i}$. When the controller is too aggressive, it overreacts on small deviations of the current components from their setpoint, resulting in additional oscillations, and thus ripple.

\subsubsection{Switching Frequency and Pulse Polarity Consistency Rule}

In Figure 4, it can be seen that FS-MBPC keeps the switch state of the 2L-VSI constant during the entire update period, while this is not the case for the other types of controllers. As a result, FS-MBPC exhibits the lowest switching losses, and its switching frequency $f_{\text {switch }}$ (defined as the number of times a switch changes its state from on to off and vice versa, averaged over all the switches and a certain time interval) always remains below the update frequency $f_{\mathfrak{u}}$ of $10 \mathrm{kHz}$. In Figure 10a, it can be noticed that, for $V_{\mathrm{dc}}=200 \mathrm{~V}$ and $N=800 \mathrm{rpm}$, it applies that $f_{\text {switch }} \approx 0.4 \cdot f_{\mathrm{u}}$. This result depends on the operating point, as will be further elaborated in Section 4.1.4. For MBPC with duty cycle calculation, on the other hand, $f_{\text {switch }} \approx f_{\mathrm{u}}$. This result can be theoretically founded. Assume, for instance, that, at the beginning of the period $T_{\mathfrak{u}}$, the null vector is applied that corresponds to closing all upper switches of the inverter. In this case, there are three active voltage vectors that require only one inverter leg to change its switch state twice, and two active voltage vectors that require two inverter legs to change their switch state twice. A similar reasoning can be followed for the second null vector. Thus, indeed, each leg switches once per $T_{\mathfrak{u}}$ on average. For the PI and DB controller, the PWM algorithm changes the switch state of each inverter leg twice per $T_{\mathbf{u}}$, resulting in $f_{\text {switch }} \approx 2 \cdot f_{\mathbf{u}}$. The difference in switching can also be noticed in Figure 11, displaying a zoomed-in view of the phase voltages for one electrical period of $9.4 \mathrm{~ms}$. These phase voltages are measured between phase $a$ and the unconnected star point of the AFPMSM with a LeCroy WaveSurfer 24 Xs oscilloscope (Chestnut Ridge, New York, 
USA) at a sample frequency of $1 \mathrm{MHz}$, when the AFPMSM is rotating with a mechanical speed of $800 \mathrm{rpm}$ and a DC-bus voltage of $200 \mathrm{~V}$ is applied.
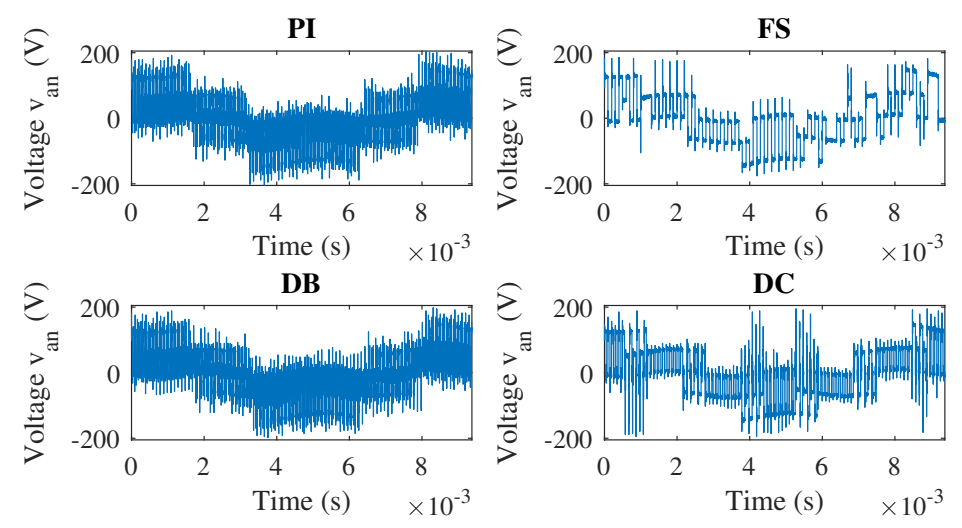

Figure 11. Phase voltage in phase $a$ for one electrical period $\left(V_{\mathrm{dc}}=200 \mathrm{~V} ; N=800 \mathrm{rpm} ; i_{q}^{*}=6 \mathrm{~A}\right)$.

Another important aspect of the applied voltage vectors is the fulfillment of the pulse polarity consistency rule (PPCR). Switch state changes violating the PPCR burden the machine isolation heavily, and must hence be avoided. Figure 9a,b show that, for FS-MBPC, $43 \%$ of the switch state changes are not in accordance with the PCCR in simulation, and $40 \%$ of them are not in accordance with the PPCR in real-life. Adding the duty cycle calculation to the algorithm increases these percentages to $50 \%$. The reason for this phenomenon is that MBPC with duty cycle calculation gives higher priority to the setpoint $i_{q}^{*}$ than to $i_{d}^{*}$ : as long as $i_{d}$ stays reasonably close to $i_{d}^{*}$, the duty cycle calculation focuses on $i_{q}$. Only when the discrepancy between $i_{d}$ and $i_{d}^{*}$ increases, the cost function forces the controller to apply a voltage vector that brings $i_{d}$ closer to $i_{d}^{*}$ again. Such a sudden change in strategy leads to additional violations of the PPCR. Since DB and PI control have a higher $f_{\text {switch }}$ than FS-MBPC, the switch state changes can happen more gradually. As a result, almost no violations of the PPCR take place anymore.

The phase voltage spectra presented in Figure 12 show that the phase voltages applied by FS-MBPC and MBPC with duty cycle calculation still contain harmonics that are too low in order to be adequately filtered out by the inductive character of the AFPMSM. The PWM algorithm used by the DB and PI controller, on the other hand, shifts the harmonics to higher orders.
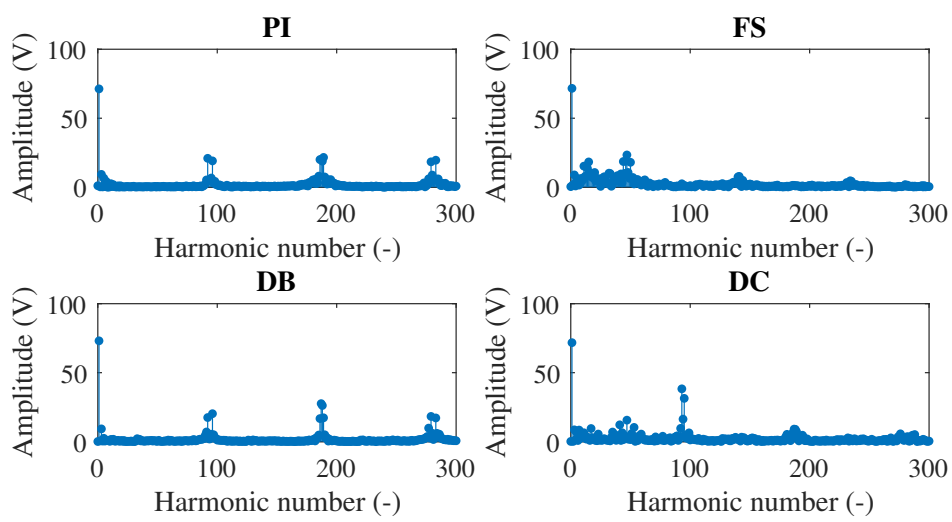

Figure 12. Voltage harmonics of phase $a\left(V_{\mathrm{dc}}=200 \mathrm{~V} ; N=800 \mathrm{rpm} ; i_{q}^{*}=6 \mathrm{~A}\right)$.

\subsubsection{Dynamic Behavior}

The dynamic performance of the controllers is quantified by means of the rise time $T_{\text {rise }}$. In order to obtain meaningful values for $T_{\text {rise }}$ under unhealthy working conditions as well, $T_{\text {rise }}$ is defined as the time it takes the controller to bring the $q$-current to its average value $\overline{i_{q}}$ reached under a specific 
setpoint. In this way, $T_{\text {rise }}$ becomes less dependent on bias $\left(i_{q}\right)$. Figure 13 illustrates this KPI for the first step applied in $i_{q}^{*}$. The average value of the rise times for all the applied steps in $i_{q}^{*}$ can be found in Figures $9 \mathrm{a}$ and 10a. The PI-controller exhibits a significantly larger rise time than the predictive controllers, as it has less system information available than the predictive controllers: it takes the PI controller in real life more than three times longer to bring $i_{q}$ to its setpoint than the predictive controllers. In simulation, the difference is smaller, but still distinct: $T_{\text {rise }}$ amounts to $1.1 \mathrm{~ms}$ for the PI controller, against maximum $0.5 \mathrm{~ms}$ for the predictive controllers. It must be noted, however, that this result strongly depends on the tuning of $K_{p}$ and $K_{i}$. Furthermore, in this paper, the authors have deliberately chosen not to add a feedforward of the back-emf to the PI controller, in order to keep this controller completely independent of the system model. Such a feedforward could improve the dynamic performance of the PI controller as well.

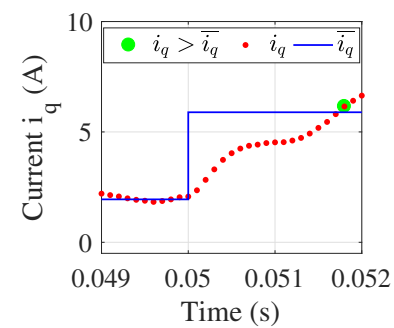

(a) PI control

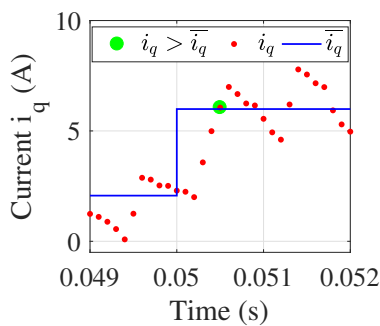

(b) FS-MBPC

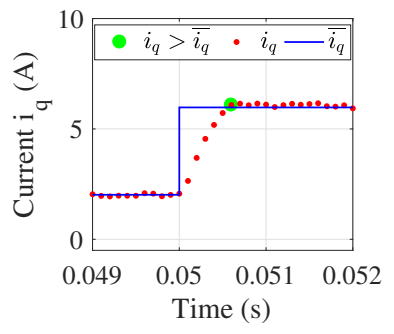

(c) DB control

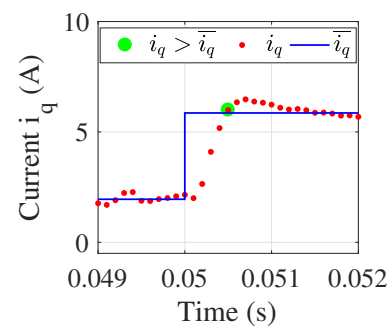

(d) MBPC with duty cycle

Figure 13. Measured rise time of the controllers under healthy working conditions.

\subsubsection{Influence of the Working Conditions}

The foregoing discussion is based on simulations and experiments conducted for $V_{\mathrm{dc}}=200 \mathrm{~V}$ and $N=800 \mathrm{rpm}$. In this section, whether the conclusions are valid for other working conditions as well is studied. Figure 14 illustrates how the simulated KPIs vary with $V_{\mathrm{dc}}$ and $N$ for the four controllers under consideration. Results are only given for DC-bus voltages that are sufficiently high to compensate for the back-emf under the considered mechanical speeds. For $200 \mathrm{rpm}, 400 \mathrm{rpm}$, $600 \mathrm{rpm}$ and $800 \mathrm{rpm}$, the magnitude of the back-emf equals, respectively, $17.78 \mathrm{~V}, 35.55 \mathrm{~V}, 53.32 \mathrm{~V}$ and $71.10 \mathrm{~V}$ in the $d q$-reference frame. It can be noticed that the KPI representing the systematic deviation of the setpoints (calculated as $\Sigma|\operatorname{bias}|=\left|\operatorname{bias}\left(i_{q}\right)\right|+\left|\operatorname{bias}\left(i_{d}\right)\right|$ ) remains low under the entire range of working conditions, for all the controllers. The current ripple $\operatorname{ripple}=\operatorname{ripple}\left(i_{q}\right)+\operatorname{ripple}\left(i_{d}\right)$, on the contrary, does vary with $V_{\mathrm{dc}}$ and $N$. For PI control, DB control, and MBPC with duty cycle, the ripple increases very slightly with increasing $N$, as oscillations in the back-emf are amplified with the speed, and the discretization of the state-space model (1) becomes less accurate. However, for the same three controllers, the ripple is independent of $V_{\mathrm{dc}}$ because the magnitude of their applicable voltage vectors can be varied between 0 and $V_{\mathrm{dc}} / 2$. For FS-MBPC, on the other hand, the magnitude of the applicable voltage vectors is restricted to 0 or $V_{\mathrm{dc}} / 2$, resulting in a ripple depending on how well $V_{\mathrm{dc}}$ and $N$ are adjusted to each other. After all, the difference between the applied voltage and the back-emf is proportional to the current derivative. A high $V_{\mathrm{dc}}$ with a low $N$ hence results in a high ripple. Furthermore, the fact that the magnitude of the active voltage vectors applicable by FS-MBPC is restricted to $V_{\mathrm{dc}} / 2$ causes $f_{\text {switch }}$ to decrease with $V_{\mathrm{dc}}$. When $V_{\mathrm{dc}}$ is high, applying an active voltage vector results in abrupt changes in $i_{q}$ and $i_{d}$, making it only advantageous to apply such an active voltage vector if it brings both $i_{q}$ and $i_{d}$ closer to their setpoints. The rest of the time, it is more appropriate to apply a null vector, as an active voltage vector would do more harm than good. For lower $V_{\mathrm{dc}}$, however, the changes in $i_{q}$ and $i_{d}$ caused by an active voltage vector are less abprupt, making it more likely that the beneficial effect of such an active voltage vector on one current component outweighs the possible adverse effect on the other current component. For $N=200 \mathrm{rpm}$, for example, a null vector is applied during $59.12 \%$ of the time when $V_{\mathrm{dc}}$ equals $80 \mathrm{~V}$, but $83.12 \%$ 
of the time when $V_{\mathrm{dc}}$ is $200 \mathrm{~V}$. Besides the dependency of $f_{\text {switch }}$ on $V_{\mathrm{dc}}$ for FS-MBPC, the speed $N$ has an effect as well. The amplified oscillations in the back-emf, and the degraded discretization of the state-space model (1) for higher $N$ result in a more frequent need to change the switch state. The general conclusion that FS-MBPC exhibits more current ripple, but less switching losses than the other types of control remains valid, as is the fact that the switch state changes of PI and DB control fulfill the PPCR more often. The difference in modulation strategy between the controllers accounts for all these features, as is explained in the previous sections. The superior dynamic performance of predictive control over PI control is observed under the entire range of working conditions as well. After all, the predictive controllers have the information of the machine model at their disposal to bring the current components faster to their setpoints. Experiments under three different working conditions-presented in Figure 15a—show the same trends.
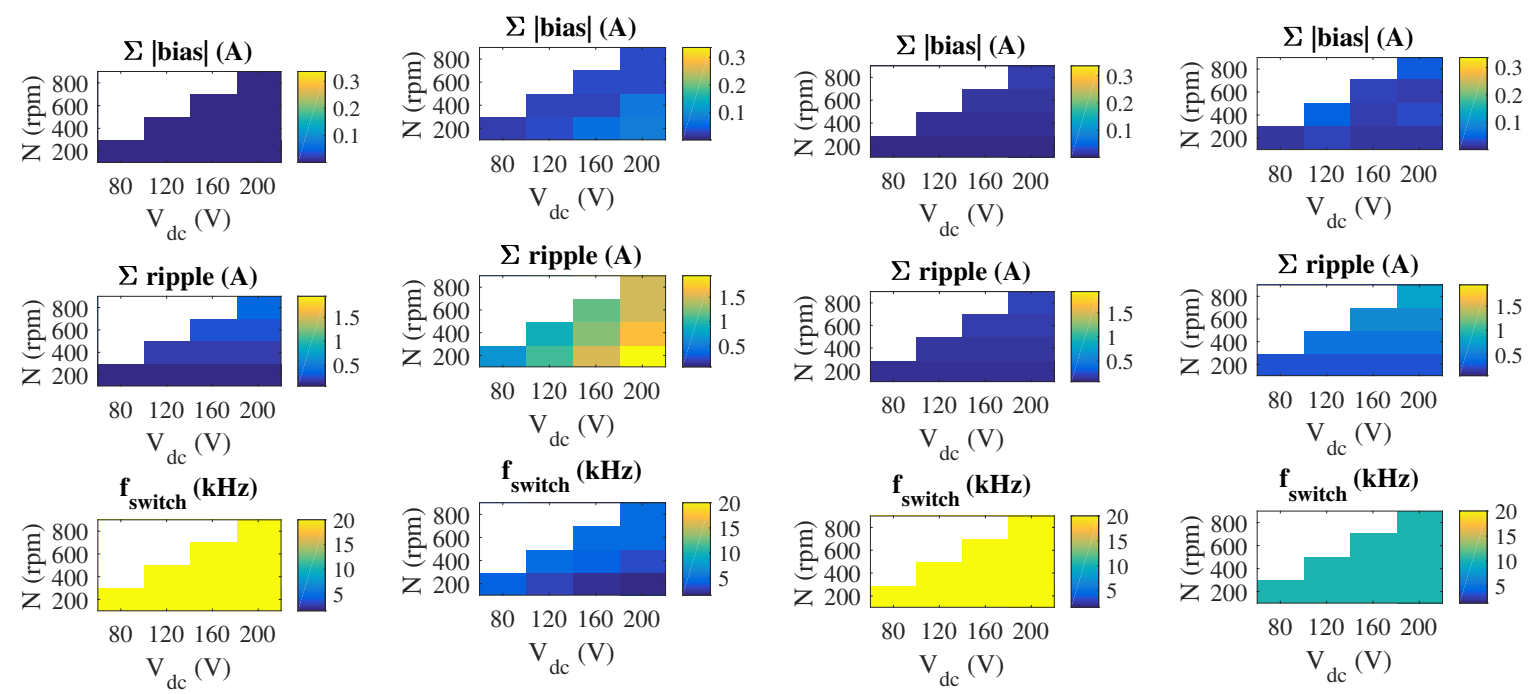

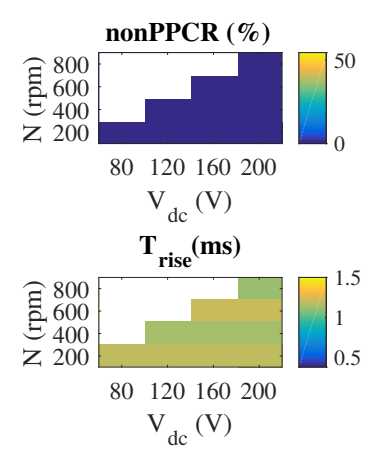

(a) PI control
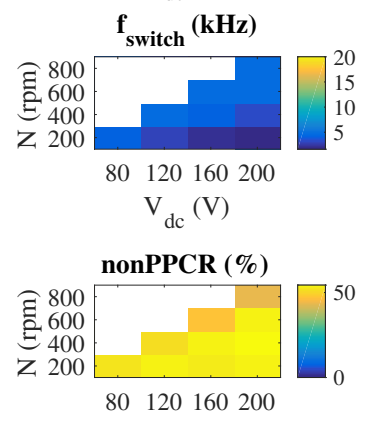

$\mathrm{V}_{\mathrm{dc}}(\mathrm{V})$

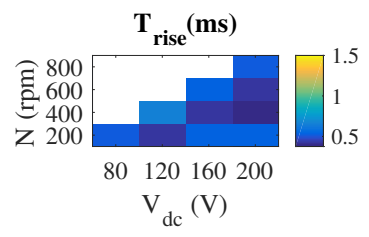

(b) FS-MBPC
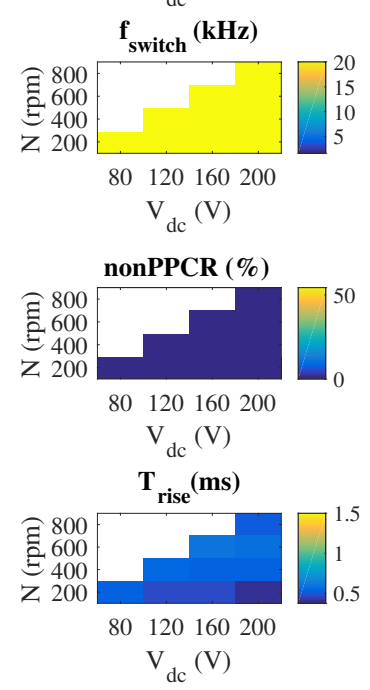

(c) DB control

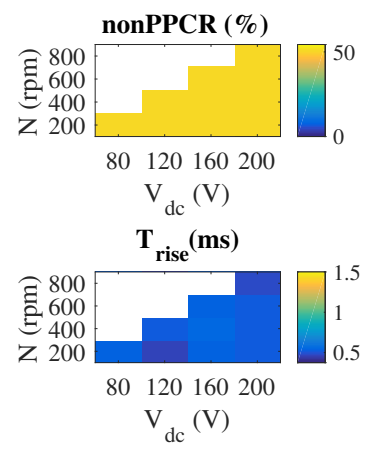

(d) MBPC with duty cycle

Figure 14. Simulated effect of DC-bus voltage $V_{\mathrm{dc}}$ and mechanical speed $N$ on the KPIs with a healthy rotor. 

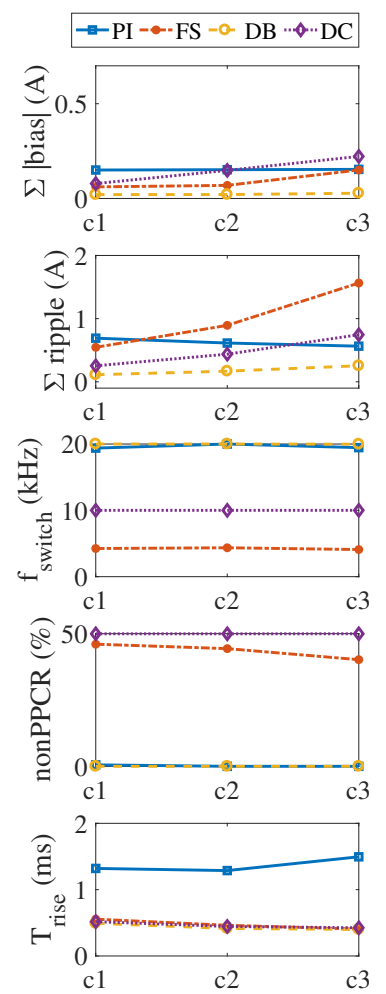

(a) healthy
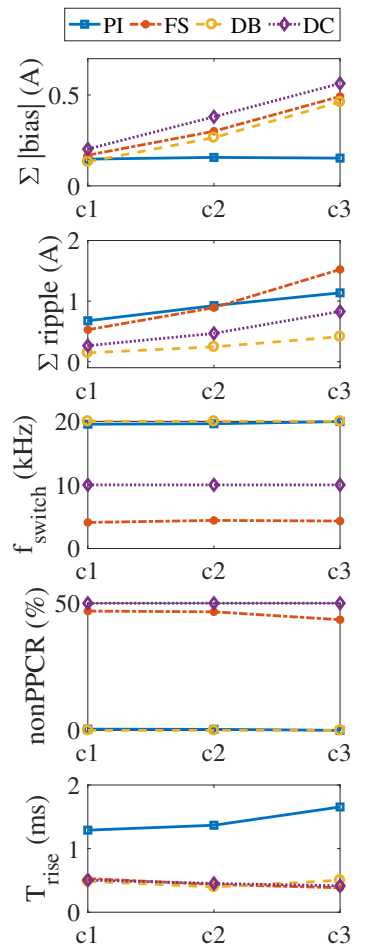

(b) faulty
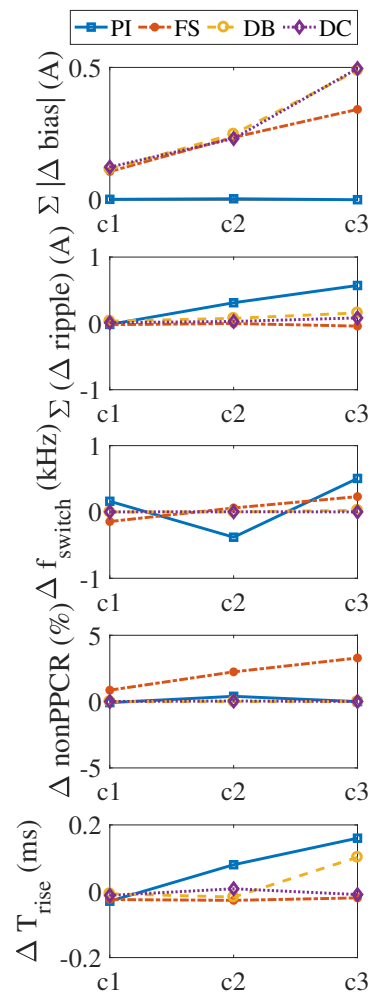

(c) effect

Figure 15. Measured effect of DC-bus voltage $V_{\mathrm{dc}}$ and mechanical speed $N$ on the KPIs with a healthy rotor. Three working conditions are tested: (c1) $V_{\mathrm{dc}}=70 \mathrm{~V}, N=200 \mathrm{rpm}$, (c2) $V_{\mathrm{dc}}=120 \mathrm{~V}, N=400 \mathrm{rpm}$, (c3) $V_{\mathrm{dc}}=200 \mathrm{~V}, \mathrm{~N}=800 \mathrm{rpm}$.

\subsection{Faulty Rotor}

The comparison of the four controllers will be repeated in this section for an AFPMSM with the faulty disc of Figure 7 as the right rotor. The partial demagnetization fault in this rotor disc is obtained by removing the complete third and fourth magnet, and a part of the eighth magnet. The model and the parameters used by the predictive controllers are not updated, and they remain the same as for the healthy rotor disc. For $V_{\mathrm{dc}}=200 \mathrm{~V}$ and $N=800 \mathrm{rpm}$, the simulation and experimental results are given in Figure 16; the KPIs are presented in Figures $9 \mathrm{~b}$ and $10 \mathrm{~b}$. Special attention will be paid to the effect of this faulty rotor on the KPIs. This effect is shown in Figures $9 \mathrm{c}$ and $10 \mathrm{c}$, where the difference $\triangle \mathrm{KPI}=\mathrm{KPI}_{\text {faulty }}-\mathrm{KPI}_{\text {healthy }}$ is presented. In Section 4.2.4, the influence of the working conditions is studied. 


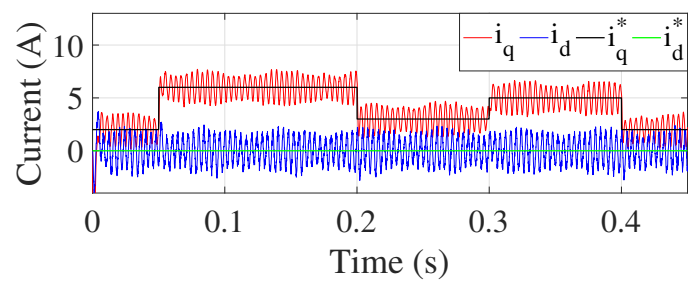

(a) simulation PI control

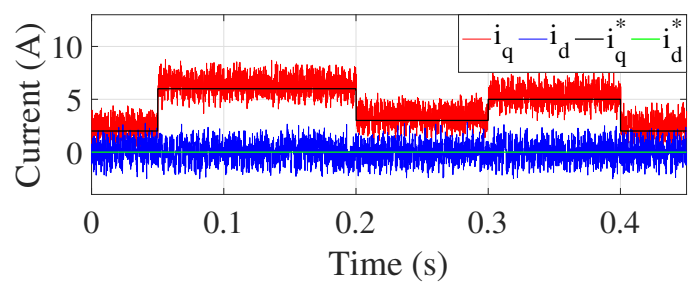

(c) simulation FS-MBPC

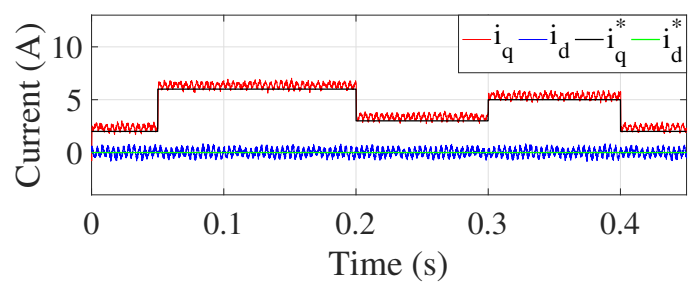

(e) simulation DB control

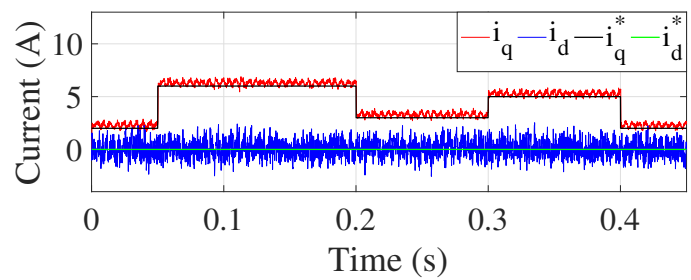

(g) simulation MBPC with duty cycle calculation

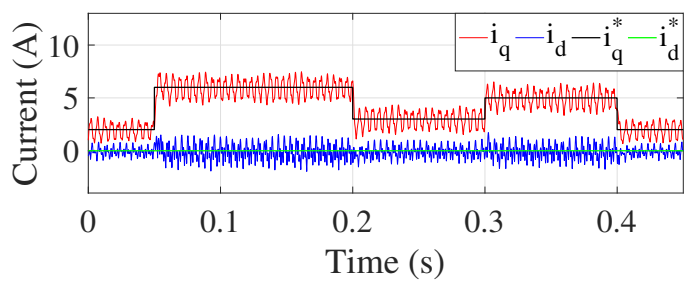

(b) experiment PI control

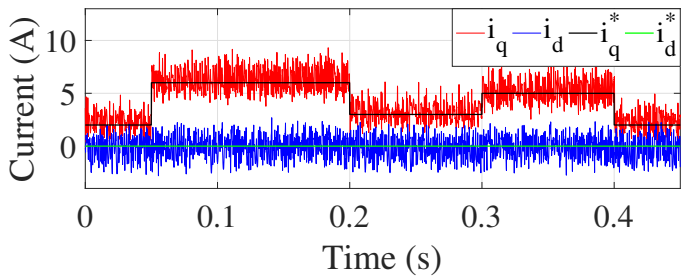

(d) experiment FS-MBPC

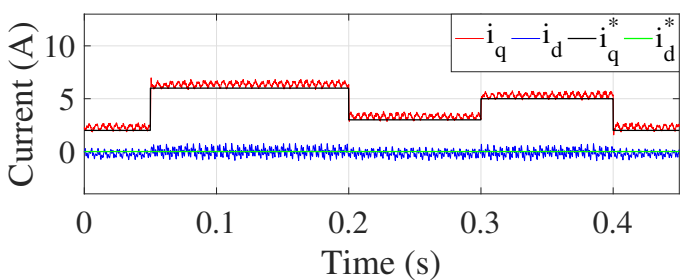

(f) experiment DB control

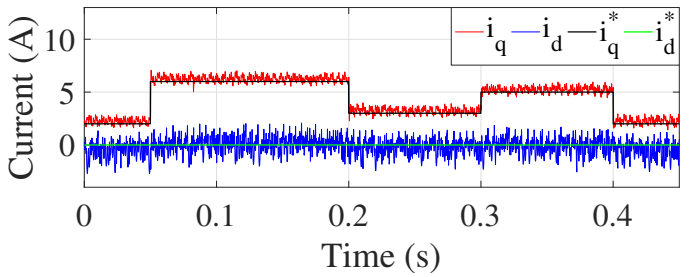

(h) experiment MBPC with duty cycle calculation

Figure 16. Simulation and experimental results for the stator current components with a defect in the $\operatorname{rotor}\left(N=800 \mathrm{rpm} ; V_{\mathrm{dc}}=200 \mathrm{~V}\right)$.

\subsubsection{Control Quality}

First of all, the demagnetization faults in the right rotor disc reduce the average value of the back-emf. As a result, the parameter $i_{\text {mag }}$ decreases to $38.69 \mathrm{~A}$ on average, as can be seen in Figure 17 . The predictive controllers-which are still using the original value of $41.77 \mathrm{~A}$ for $i_{\text {mag }}$ that is valid for the healthy machine-overestimate the back-emf, and hence apply a voltage that overcompensates the actual back-emf. As a result, $i_{q}$ is systematically a bit higher than $i_{q}^{*}$. Compared to the healthy situation, $\operatorname{bias}\left(i_{q}\right)$ increases with approximately $0.3 \mathrm{~A}$ for all the predictive controllers in simulation. The effect on bias $\left(i_{d}\right)$ is less pronounced, as $i_{d}$ is only indirectly affected by $i_{\text {mag. }}$. According to the experimental results of Figure 10c, the parameter mismatch in $i_{\text {mag }}$ has slightly less effect on standard FS-MBPC than on the other two predictive controllers: $\operatorname{bias}\left(i_{q}\right)$ rises with only $0.23 \mathrm{~A}$ for FS-MBPC, while the increase amounts to $0.34 \mathrm{~A}$ for DB control and MBPC with duty cycle calculation. FS-MBPC depends only on the system model (1) - and thus on $i_{\mathrm{mag}}$ - to determine the most optimal switch state. The other predictive controllers, on the other hand, also rely on this model to determine the magnitude and-in 
case of DB control-the direction of the on average applied voltage vector. Since the PI controller does not depend on the system model—and thus not on the parameter $i_{\text {mag }}$-to compute its reference voltages, the faulty rotor disc has no effect on the bias in both current components for this controller.

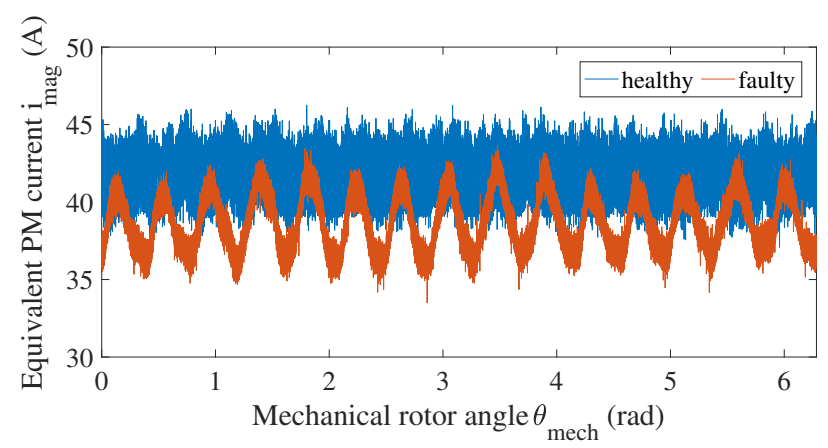

Figure 17. Effect of the demagnetization fault on the equivalent permanent magnet current $i_{\text {mag }}$.

Apart from the reduction in the average value of the back-emf, the faulty rotor disc also introduces asymmetrical flux patterns, causing the back-emf to vary over the circumference of the rotor, as can be seen in Figure 17. Since the PI controller is quite aggressive-as it is tuned to be able to follow the fast variations in $i_{q}^{*}$-it reacts strongly to these variations in the back-emf. This results in $0.52 \mathrm{~A}$ additional current ripple in $i_{q}$, and $0.60 \mathrm{~A}$ additional ripple in $i_{d}$ in simulation. In real life, the effect is less pronounced: ripple $\left(i_{q}\right)$ rises with $0.48 \mathrm{~A}$, and ripple $\left(i_{d}\right)$ with only $0.09 \mathrm{~A}$. The back-emf variations have less influence on the predictive controllers, as they continue to react in the same way as for the healthy machine. They cause a slight increase in the current ripple of DB control and MBPC with duty calculation, but their effect on standard FS-MBPC cannot be discerned from the current ripple that is, by default, present for this type of control. This default ripple under healthy circumstances for standard FS-MBPC is even higher than the current ripple displayed by the other two predictive controllers under the partial demagnetization fault.

\subsubsection{Switching Frequency and Pulse Polarity Consistency Rule}

The modulation strategies of the controllers have not been changed for the unhealthy machine. The KPIs in Figures $9 \mathrm{c}$ and 10c hence show that the demagnetization faults have almost no effect on $f_{\text {switch }}$ and the fulfillment of the PPCR. The maximum effect is limited to a rise of $500 \mathrm{~Hz}$ in $f_{\text {switch }}$ for PI control in real life, and less than $5 \%$ additional switch state changes violating the PPCR for standard FS-MBPC in simulation. The voltage waveforms under the demagnetization fault are very similar to the waveforms under healthy conditions, shown in Figure 11.

\subsubsection{Dynamic Behavior}

Concerning the rise time of the controllers, demagnetization has a limited effect as well. According to the simulation results of Figure 9c, $T_{\text {rise }}$ decreases with only $25 \mu \mathrm{s}$ for MBPC with duty cycle calculation, and increases with $400 \mu \mathrm{s}$ and $225 \mu \mathrm{s}$ for, respectively, PI control and standard FS-MBPC. For DB control, $T_{\text {rise }}$ even remains the same. The experimental results of Figure 10c, on the other hand, give an increase in $T_{\text {rise }}$ of respectively $160 \mu$ s and $103 \mu$ s for PI and DB control, and a decrease of, respectively, 20 and $10 \mu$ s for standard FS-MBPC and MBPC with duty cycle calculation.

\subsubsection{Influence of the Working Conditions}

The foregoing discussion is based on simulations and experiments conducted at $V_{\mathrm{dc}}=200 \mathrm{~V}$ and $N=800 \mathrm{rpm}$. In this section, it will be examined whether the conclusions concerning the KPIs are valid under other working conditions as well. Figures 18 and 19 present the effect of $V_{\mathrm{dc}}$ and $N$ on the KPIs for the AFPMSM with a faulty rotor, and on the difference between the KPIs for the faulty and healthy rotors, respectively. Due to the demagnetization fault, the average back-emfs have lowered 
to $16.47 \mathrm{~V}, 32.93 \mathrm{~V}, 49.40 \mathrm{~V}$ and $65.86 \mathrm{~V}$ for, respectively, $200 \mathrm{rpm}, 400 \mathrm{rpm}, 600 \mathrm{rpm}$ and $800 \mathrm{rpm}$. Concerning the systematic deviation of the current components from their setpoint, it can be concluded that the bias increases with increasing $N$ for the predictive controllers. This is a result of the fact that the effect of the demagnetization fault on the back-emf is enhanced with increasing speed. The current ripple shows the same trends as for the healthy rotor. The effect of the demagnetization fault on the current ripple is scaled up by the speed. Indeed, a larger mechanical speed $\mathrm{N}$-and thus a larger electrical speed $\omega$-causes a more severe overestimation of the back-emf in model (1), and thus in an applied voltage that overcompensates the back-emf. As a result of this overcompensation, the current derivative-and hence the current ripple-increases. This effect is more pronounced for DB control than for the other types of predictive controllers, as DB control uses the system model to determine both the magnitude and the direction of the average applied voltage vector, while for MBPC with a duty cycle and FS-MBPC, at least the direction of the applied voltage vector is predetermined. Concerning $f_{\text {switch }}$, the fulfillment of the PPCR, and the dynamic performance of the controllers, the obtained results are similar to the results for the healthy rotor. Experiments under three different working conditions-presented in Figure 15b,c-show the same trends. In general, the conclusions obtained under $V_{\mathrm{dc}}=200 \mathrm{~V}$ and $N=800 \mathrm{rpm}$ are valid under the entire range of considered working conditions.
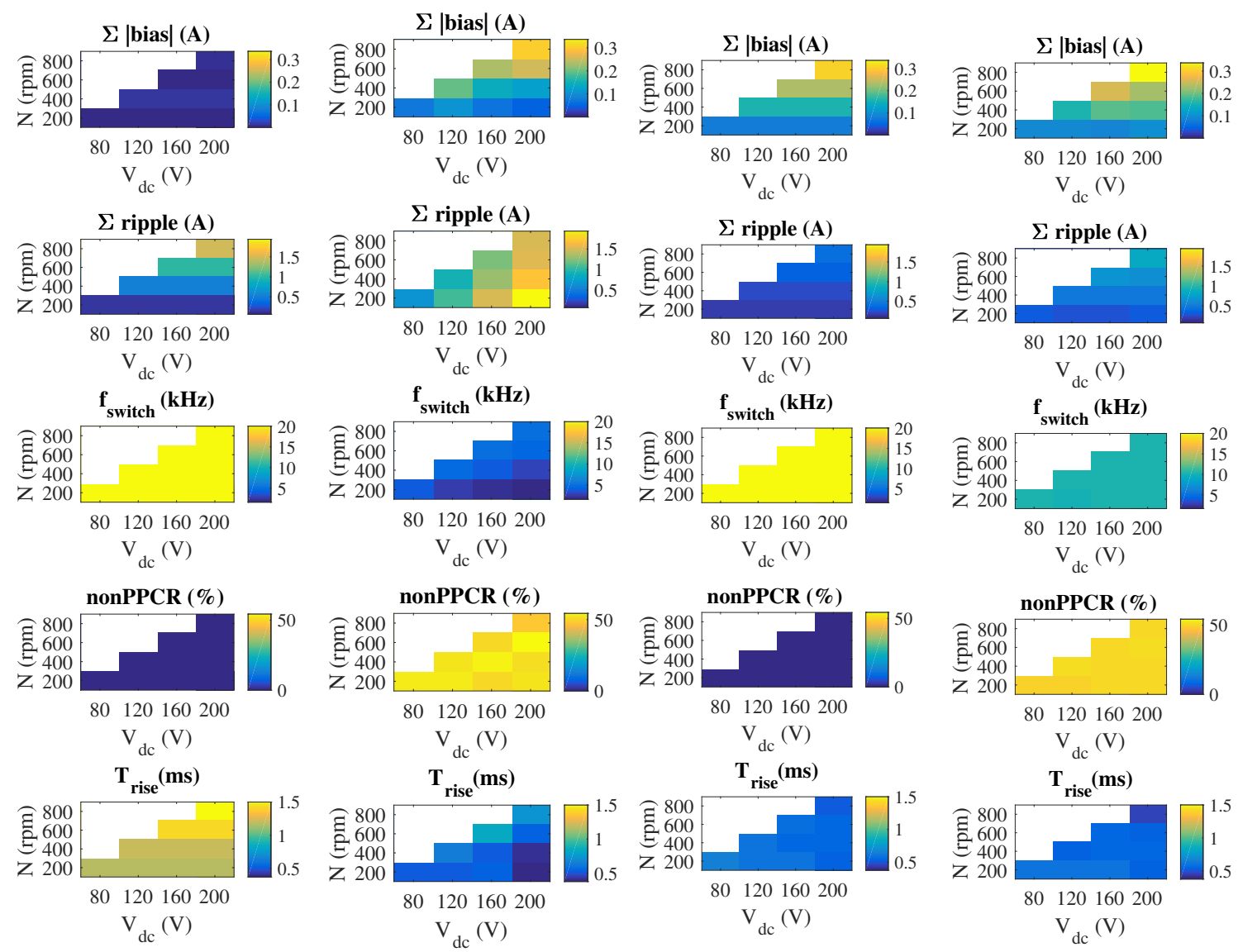

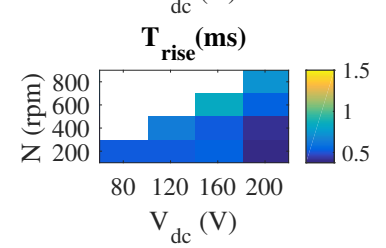

(b) FS-MBPC

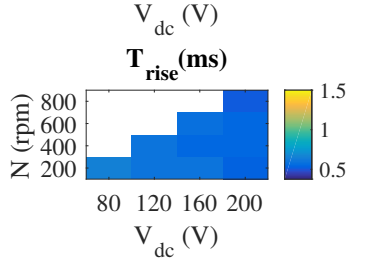

(c) DB control (d) MBPC with duty cycle

Figure 18. Effect of DC-bus voltage $V_{\mathrm{dc}}$ and mechanical speed $N$ on the KPIs for a faulty rotor. 

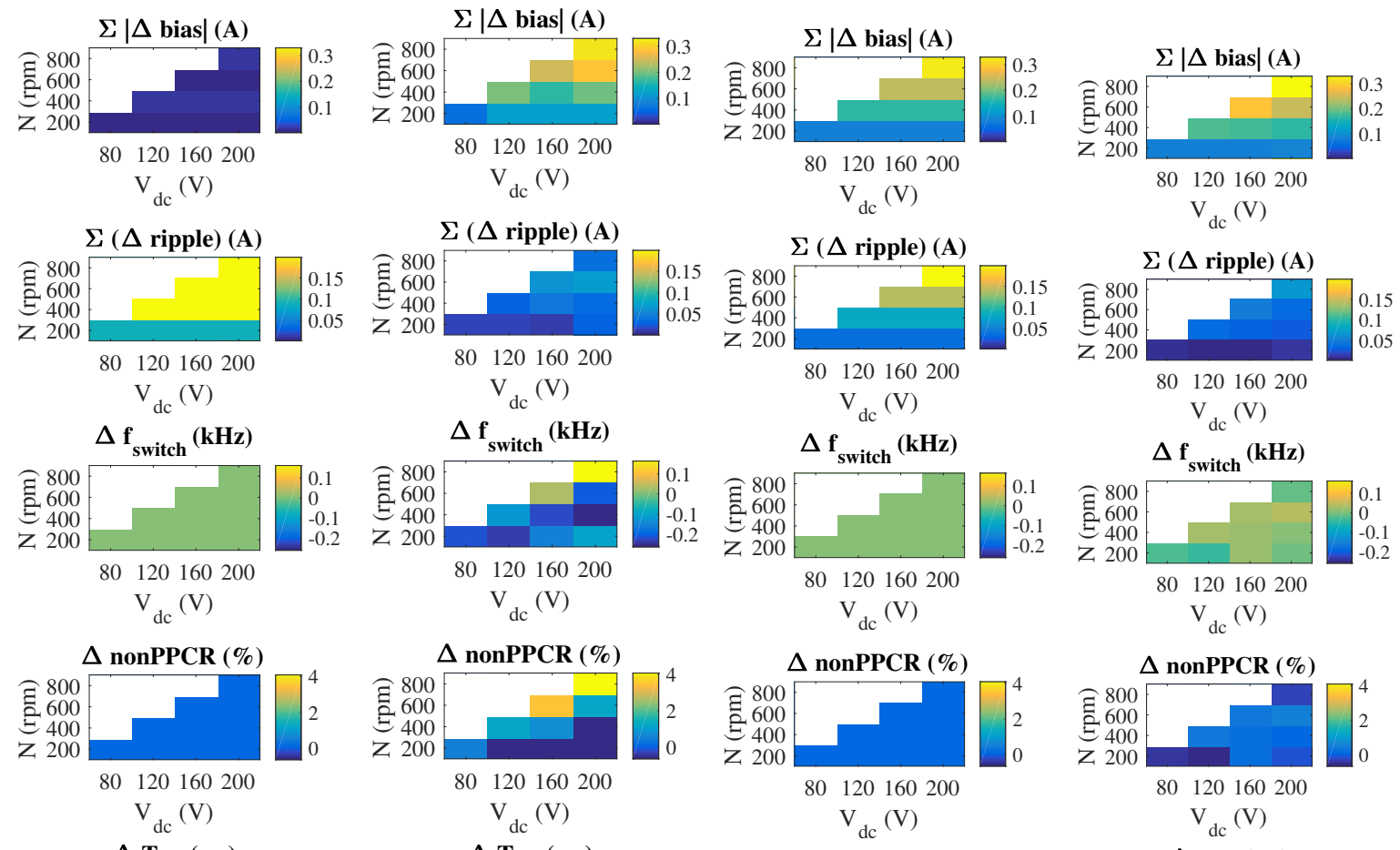

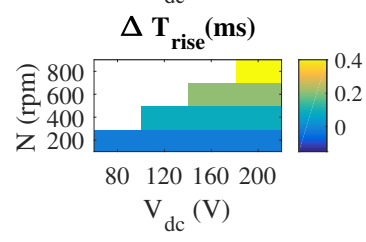

(a) PI control
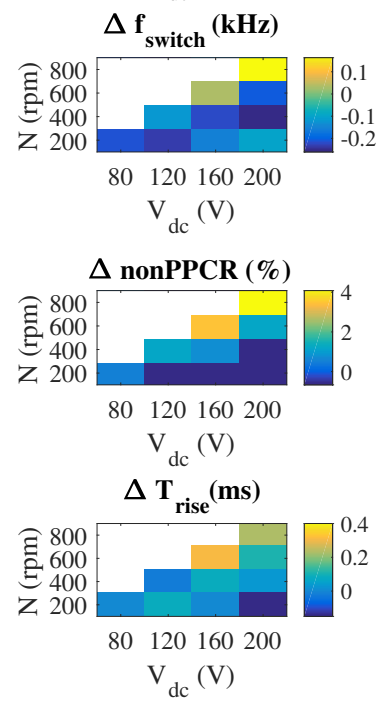

(b) FS-MBPC
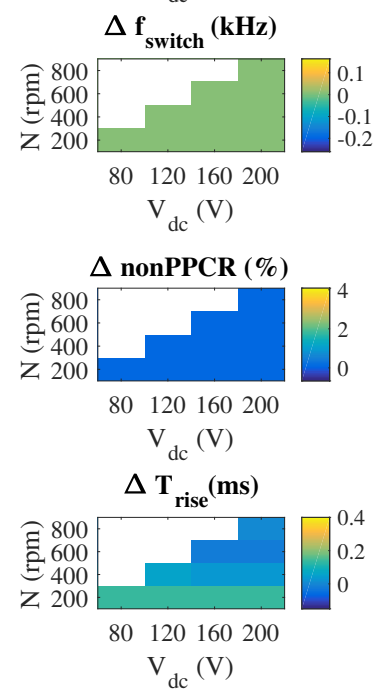

(c) DB control

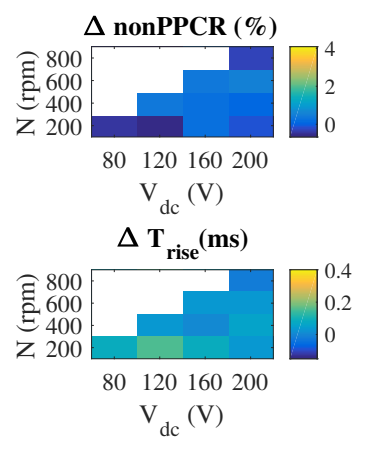

(d) MBPC with duty cycle

Figure 19. Effect of DC-bus voltage $V_{\mathrm{dc}}$ and mechanical speed $N$ on the difference between the KPIs for a faulty and a healthy rotor.

\section{Conclusions}

Three different predictive current controllers and a PI controller have been compared, both in simulation and in experiments, under different working conditions. The three predictive controllers were FS-MBPC, DB control and MBPC with duty cycle calculation, and the studied drive was an AFPMSM with surface mounted permanent magnets and a YASA topology, fed by a three-phase 2L-VSI. The main aim of the comparison was to analyze the effect of partial demagnetization on the performance of the predictive controllers. It was observed that the effect of the applied demagnetization fault is limited to an increase in bias in the current components, a phenomenon that is not observed for the model-independent PI controller. DB control and MBPC with duty cycle calculation also suffer from a slight increase in ripple in $i_{q}$. However, even with this increase, their current ripple remains significantly lower than for standard FS-MBPC, especially for the DB controller. Violation of the PPCR, switching losses and rise time are not affected by the demagnetization fault. Overall, the DB controller displays the best performance under the applied partial demagnetization fault.

Author Contributions: Conceptualization, J.D., H.V. and P.S.; Funding acquisition, P.S.; Investigation, L.V.; Methodology, L.V.; Resources, H.V. and P.S.; Software, L.V. and J.D.; Supervision, J.D., H.V. and P.S.; Validation, L.V., J.D. and H.V.; Visualization, L.V.; Writing—original draft, L.V.; Writing-review and editing, J.D., H.V., F.D.B. and P.S.

Funding: This research received no external funding.

Conflicts of Interest: The authors declare no conflict of interest. 


\section{Abbreviations}

The following abbreviations are used in this manuscript:

2L-VSI two-level voltage source inverter

AFPMSM axial flux permanent magnet synchronous machine

DB deadbeat

FS-MBPC finite-set model based predictive control

IM induction motor

KPI key performance indicator

MBPC model based predictive control

PM permanent magnet

PMSM permanent magnet synchronous machine

PWM pulse width modulation

YASA yokeless and segmented armature

\section{References}

1. Vansompel, H.; Sergeant, P.; Dupre, L.; Van den Bossche, A. Axial-Flux PM Machines With Variable Air Gap. IEEE Trans. Ind. Electron. 2014, 61, 730-737. [CrossRef]

2. Park, Y.; Koo, M.; Jang, S.; Choi, J.; You, D. Performance Evaluation of Radial- and Axial-Flux PM Wind Power Generators With Mechanical Energy Storage System. IEEE Trans. Energy Convers. 2015, 30, 237-245. [CrossRef]

3. Morel, F.; Lin-Shi, X.; Retif, J.M.; Allard, B.; Buttay, C. A Comparative Study of Predictive Current Control Schemes for a Permanent-Magnet Synchronous Machine Drive. IEEE Trans. Ind. Electron. 2009, 56, 2715-2728. [CrossRef]

4. Verkroost, L.; Druant, J.; Vansompel, H.; De Belie, F.; Sergeant, P. Predictive Current Control vs. PI Control for Surface Mounted Permanent Magnet Machines. In Proceedings of the 2018 XXIII International Conference on Electrical Machines (ICEM), Alexandroupoli, Greece, 3-6 September 2018; p. 7.

5. Vyncke, T.J.; Thielemans, S.; Melkebeek, J.A. Finite-Set Model-Based Predictive Control for Flying-Capacitor Converters: Cost Function Design and Efficient FPGA Implementation. IEEE Trans. Ind. Inform. 2013, 9, 1113-1121. [CrossRef]

6. Kouro, S.; Cortes, P.; Vargas, R.; Ammann, U.; Rodriguez, J. Model Predictive Control-A Simple and Powerful Method to Control Power Converters. IEEE Trans. Ind. Electron. 2009, 56, 1826-1838. [CrossRef]

7. Li, P.; Li, R.; Feng, H. Total Harmonic Distortion Oriented Finite Control Set Model Predictive Control for Single-Phase Inverters. Energies 2018, 11, 3467. [CrossRef]

8. Chan, R.; Kwak, S. Model-Based Predictive Current Control Method with Constant Switching Frequency for Single-Phase Voltage Source Inverters. Energies 2017, 10, 1927. [CrossRef]

9. Xie, W.; Wang, X.; Wang, F.; Xu, W.; Kennel, R.M.; Gerling, D.; Lorenz, R.D. Finite-Control-Set Model Predictive Torque Control With a Deadbeat Solution for PMSM Drives. IEEE Trans. Ind. Electron. 2015, 62, 5402-5410. [CrossRef]

10. Zhu, H.; Xiao, X.; Li, Y. Torque Ripple Reduction of the Torque Predictive Control Scheme for Permanent-Magnet Synchronous Motors. IEEE Trans. Ind. Electron. 2012, 59, 871-877. [CrossRef]

11. Kenny, B.; Lorenz, R. Stator- and rotor-flux-based deadbeat direct torque control of induction machines. IEEE Trans. Ind. Appl. 2003, 39, 1093-1101. [CrossRef]

12. Zhang, Y.; Yang, H. Model Predictive Torque Control of Induction Motor Drives With Optimal Duty Cycle Control. IEEE Trans. Power Electron. 2014, 29, 6593-6603. [CrossRef]

13. Abdelrahem, M.; Hackl, C.M.; Zhang, Z.; Kennel, R. Robust Predictive Control for Direct-Driven Surface-Mounted Permanent-Magnet Synchronous Generators Without Mechanical Sensors. IEEE Trans. Energy Convers. 2018, 33, 179-189. [CrossRef]

14. Ibrahim Mohamed, Y.A.R. Direct instantaneous torque control in direct drive permanent magnet synchronous motors-A new approach. IEEE Trans. Energy Convers. 2007, 22, 829-838. [CrossRef]

15. Li, J.; Huang, X.; Niu, F.; You, C.; Wu, L.; Fang, Y. Prediction Error Analysis of Finite-Control-Set Model Predictive Current Control for IPMSMs. Energies 2018, 11, 2051. [CrossRef] 
16. Kim, J.; Hong, J.; Kim, H. Improved direct deadbeat voltage control with an actively damped inductor-capacitor plant model in an islanded AC microgrid. Energies 2016, 9, 978. [CrossRef]

17. Yang, M.; Lang, X.; Long, J.; Xu, D. Flux Immunity Robust Predictive Current Control With Incremental Model and Extended State Observer for PMSM Drive. IEEE Trans. Power Electron. 2017, 32, 9267-9279. [CrossRef]

18. Sjökvist, S.; Eriksson, S. Investigation of Permanent Magnet Demagnetization in Synchronous Machines during Multiple Short-Circuit Fault Conditions. Energies 2017, 10, 1638. [CrossRef]

19. Goktas, T.; Zafarani, M.; Akin, B. Discernment of Broken Magnet and Static Eccentricity Faults in Permanent Magnet Synchronous Motors. IEEE Trans. Energy Convers. 2016, 31, 585-594. [CrossRef]

20. Haddad, R.Z.; Strangas, E.G. On the Accuracy of Fault Detection and Separation in Permanent Magnet Synchronous Machines Using MCSA/MVSA and LDA. IEEE Trans. Energy Convers. 2016, 31, 924-934. [CrossRef]

21. Sarikhani, A.; Mohammed, O.A. Demagnetization Control for Reliable Flux Weakening Control in PM Synchronous Machine. IEEE Trans. Energy Convers. 2012, 27, 1046-1055. [CrossRef]

22. Alexandrou, A.D.; Adamopoulos, N.K.; Kladas, A.G. Development of a Constant Switching Frequency Deadbeat Predictive Control Technique for Field-Oriented Synchronous Permanent-Magnet Motor Drive. IEEE Trans. Ind. Electron. 2016, 63, 5167-5175. [CrossRef]

23. Underwood, S.J.; Husain, I. Online Parameter Estimation and Adaptive Control of Permanent-Magnet Synchronous Machines. IEEE Trans. Ind. Electron. 2010, 57, 2435-2443. [CrossRef]

24. Turker, T.; Buyukkeles, U.; Bakan, A.F. A Robust Predictive Current Controller for PMSM Drives. IEEE Trans. Ind. Electron. 2016, 63, 3906-3914. [CrossRef]

25. Du, G.; Li, J.; Du, F.; Liu, Z. A Robust Digital Control Strategy Using Error Correction Based on the Discrete Lyapunov Theorem. Energies 2018, 11, 848.

26. Siami, M.; Khaburi, D.A.; Abbaszadeh, A.; Rodríguez, J. Robustness Improvement of Predictive Current Control Using Prediction Error Correction for Permanent-Magnet Synchronous Machines. IEEE Trans. Ind. Electron. 2016, 63, 3458-3466. [CrossRef]

27. Zhang, X.; Hou, B.; Mei, Y. Deadbeat Predictive Current Control of Permanent-Magnet Synchronous Motors with Stator Current and Disturbance Observer. IEEE Trans. Power Electron. 2017, 32, 3818-3834. [CrossRef]

28. Zhang, C.; Wu, G.; Rong, F.; Feng, J.; Jia, L.; He, J.; Huang, S. Robust Fault-Tolerant Predictive Current Control for Permanent Magnet Synchronous Motors Considering Demagnetization Fault. IEEE Trans. Ind. Electron. 2018, 65, 5324-5334. [CrossRef]

29. Hu, F.; Luo, D.; Luo, C.; Long, Z.; Wu, G. Cascaded Robust Fault-Tolerant Predictive Control for PMSM Drives. Energies 2018, 11, 3087. [CrossRef]

30. Wu, H.; Su, W.; Liu, Z. PID controllers: Design and tuning methods. In Proceedings of the 2014 9th IEEE Conference on Industrial Electronics and Applications (ICIEA), Hangzhou, China, 9-11 June 2014; pp. 808-813.

31. Nemec, M.; Nedeljkovic, D.; Ambrozic, V. Predictive torque control of induction machines using immediate flux control. IEEE Trans. Ind. Electron. 2007, 54, 2009-2017. [CrossRef]

(C) 2019 by the authors. Licensee MDPI, Basel, Switzerland. This article is an open access article distributed under the terms and conditions of the Creative Commons Attribution (CC BY) license (http:/ / creativecommons.org/licenses/by/4.0/). 